\title{
KECERDASAN INTERPERSONAL HUMANISTIK DALAM PERSPEKTIF Al-QUR'AN
}

\author{
EDY JUNAEDI SASTRADIHARJA \\ Institut PTIQ Jakarta \\ edyjs1706@ptiq.ac.id \\ FARIZAL MS \\ Institut PTIQ Jakarta \\ farizalmarlius64@gmail.com \\ AL FIRDAUS \\ Institut PTIQ Jakarta \\ dausalfirdaus@gmail.com
}

\begin{abstract}
ABSTRAK
Penelitian ini tentang kecerdasan interpersonal humanistik dalam perspektif Al-Qur'an mengusung teori humanis. Hal ini berdasarkan deskripsi Al-Qur'an mengenai intraksi manusia yang satu dengan yang lain. Bahwa manusia yang hidup berdampingan harus saling memahami agar terbentuknya ketentraman majemuk bagi lingkungan sekitarnya. menarik yang ditemukan dalam penelitian ini. Bahwa kecerdasan interpersonal humanistik terbagi menjadi dua. Pertama Internal. Kedua eskternal. Pertama, Internal berisi: a. Repleks Positif terhadap orang yang berkebutuhan khusus, yang diterangkan dalam Surat 'Abasa/80: 1-4, b. Tidak Menyakiti dengan Tangan, yang termaktub dalam Surat AlLahab/111:1-5 dan Surat Al-Humazah/104:1-2, c. Berbagi /Share Nasehat, yang dijelaskan pada Surat Al-'Ashar/103: 1-3, d. Kepekaan Intelektualitas, yang terdapat Surat Al'Alaq/96:1-7, e. Tidak Over Konfident, yang tertulis pada Surat al-Hujarat/49:10-13, f. Pendidikan Dialog Efektif, yang tersurat pada Surat Lukman/31:12-19, g. Pendidikan Dialog Ketegasan, pada Surat Maryam/19:41-46, h. percaya Tuhan/ Beliveng good, yang tercantum Surat Al-Ikhlas/112:1-3. Kedua, Eksternal berisi: a. Menjaga Toleransi, yang dijelaskan Surat Al-Kafirun/109:1-6, b. Tidak berlebihan. Lebih baik minimalis, yang diterangkan dalam Surat At-Takastur/ 102:1-2, c. Menjaga Iman dan Keamanan, yang dijelaskan Surat Quraisy/106:1-4, d. Menjaga Dialog yang seha,t terdapat dalam Surat Thaha/20:41-44. Ketiga, Kecerdasan interpersonal humanistik ini dapat diterapkan pada pendidikan Islam. Yang menekankan pada aspek berhubungan dengan orang lain secara luas. Tidak hanya pada tataran teoritis tapi pada praktis dapat diterapkan dengan pembelajaran sejak dini. Karena tujuan pendidikan sejatinya adalah untuk mengajarkan orang lain berbuat baik pada sesama. Keempat, Kecerdasan interpersonal humanistik jika diimplementasikan akan menimbulkan ketentraman majemuk atau rahmatal lil'alamîn bagi dirinya dan sekitarnya. Metode yang digunakan dalam penelitian ini adalah metode analisis diskriptif dan konstekstual. Sedangkan pendekatan yang digunakan adalah pendekatan kualitatif.
\end{abstract}

Keyword: Kecerdasan Interperonal, Humanistik, dan Al-Qur'an 


\section{ABSTRACT}

The conclusion of this thesis is: humanistic interpersonal intelligence in the perspective of the Koran/Qur'an. Carrying the humanist theory, this is based on the Qur'an's description of the human interaction with one another. That human life must coexist with each other to understand each other in order to form multiple complexes in the surrounding environment. The method used in this study is descriptive and contextual analysis, while approach used is a qualitative approach. The interesting thing which founded in this study is humanistic interpersonal intelligence is divided into two types; Internal and External. First, internal contains of: a. Positive replication of people with special needs, which is explained in the Surah 'Abasa/80:1-4, b. Not hurting by hands, which is contained in Surah Al-Lahab/111:1-5 and Surah Al-Humazah/104: 1-2, c. Sharing advice, which is explained in Surah Al"Ashr/103: 1-3, d. Intellectual sensitivity, which is found in Surah Al-'Alaq/96:1-7, e. Not Over Confidence, which is written in surah Al-Hujarat/49:10-13, f. Effective dialogue education, which is written in Surah Luqman/31: 12-19, g. Intelligence dialogue education, in Surah Maryam/19:41-46, h. Believe in God (Allah), which is listed in Surah Al-Ikhlas /112:13. Second, External contains of: a. Maintaining tolerance, which is explained in Surah AlKafirun/109: 1-6, b. Not excessive, simple is better, which is explained in Surah AtTakastur/102:1-2, c. Maintaining faith and security, which is explained in Surah Quraisy/106:1-4, d. Maintaining healthy dialogue, which is found in Surah Thaha/20: 41-44. Third, humanistic interpersonal intelligence can be applied to Islamic education. Which emphasizes aspects of dealing with others widely. Not only at the theoretical level but also at the practical level can be applied with early learning. It is because the true purpose of education is to teach others to do well to all. Fourth, if humanistic interpersonal intelligence is implemented by people, it will be lead to compound tranquility or Rahmatan lill'alamiin for themselves and their surrounding.

Keyword: interpersonal intelligence, humanistic, the Koran 


\section{A. PENDAHULUAN}

Media sosial memiliki peran penting merubah masyarakat jika tidak digunakan dengan positif. Yang jadi pertanyaan kita sekarang dengan adanya berbagai faktor tersebut. Sebagai seorang Muslim harus siap menghadapi hal tersebut. Tentunya, dengan tuntunan wahyu dari Allah dan kecerdasan. Entah, kecerdasan interpersonal, visual, kenestetik, verbal. Tapi disini Daniel Goleman tidak menambahkan kecerdasan spiritual. Sebelum Daniel Goleman ada tokoh Psikologi Harvard bernama Howard Gardner yang mengembangkan kecerdasan majemuk atau Multiple Intelligences. ${ }^{1}$

Menurut Gardner Interpersonal (Social) yang dikutip oleh Anderson:" Interpersonal (Social): Learn best through relating to other people's feelings and emotional health; demonstrate high empathic proficiencies. therapists, psychologists, $H R$ professionals, politicians, educators, clergy, doctors, and coaches". 2 Kecerdasan interpersonal dalam social adalah belajar terbaik melalui berhubungan dengan perasaan dan orang lain kesehatan emosional; menunjukkan keahlian empatik yang tinggi. terapis, psikolog, profesional SDM, politisi, pendidik, pendeta, dokter,dan pelatih.

Sedangkan Goleman mengatakan kecerdasan interpersonal yang diutarakannya. "Inter personal intelligence is the ability to understand other people: what motivates them, how they work, how to work cooperatively with them". ${ }^{3}$ Kecerdasan interpersonal ialah kemampuan untuk memahami orang lain: apa yang memotivasi mereka, bagaimana mereka bekerja, bagaimana bekerja secara kooperatif dengan mereka. Magister Manajemen Pendidikan Islam Institut PTIQ Jakarta Pada era modern telah ditemukan teori yang mengatasnamakan humanistik. Walaupun sejatinya penulis sendiri masih berpandangan skeptis (meminjam istilah David Hume, ahli filsafat modern). ${ }^{4}$

Salah satu yang peneliti tawarkan untuk menanggapi persoalan tersebut adalah kecerdasan interpersonal humanistik dalam persepektif Al-Qur'an. Bagaimana kecerdasan interpersonal humanistik dalam Al-Qur'an dan Korelasi kecerdasan interpersonal untuk memberikan salah satu alternatif yang sedang dihadapi bangsa ini. Bangsa ini memiliki SDM yang bagus. Tapi SDM yang bagus harus diberikan sebuah nutrisi agar SDM tersebut terus menghasilkan dan memberi manfaat untuk bangsa ini. Seperti yang ditulis oleh M. Darwis Hude tentang emosi dalam Al-Qur'an. Bahwa emosi negatif sedapat mungkin untuk diredam dan

${ }^{1}$ Brent Anderson, Using DR. Howard Gardner's Theory of Multiple Intelligence to Connect 4th-8th Grade Student to Nature: (Hamline University, 2017).

2 Brent Anderson, Using DR. Howard Gardner's Theory of Multiple Intelligence to Connect 4th-8th Grade Student to Nature: (Hamline University, 2017), 28-29

3 Daniel Goleman, Emotional Intelligence, Why It Can Matter More Than IQ), Library of Unviolent Revolution, UnviolentPeacemaker at ThePirateBay.@Created by PDF to ePub, 81 t.th.

${ }^{4}$ David Hume terkenal di barat dan lahir di Skotlandia. Karyanya yang terkenal The History of England. 
doi.org/10.36671/andragogi.v1i3.66

sebaliknya emosi positif ditumbuhkan untuk membangun apa yang ada dalam diri manusia. ${ }^{5}$ Penulisan ini hendak mengkaji kecerdasan interpersonal humantistik dalam persepektif Al-Qur'an.

Pada Surat Ar-rahman/55: 3-4. Bahwa Allah Swt mengajarkan Al-Qur'an, menciptakan manusia dan mengajarkan pandai bicara. Bicara adalah penting dalam diri manusia. Karena bicara merupakan bentuk aktualisasi apa yang ada dalam diri manusia. Dengan bicaralah orang lain paham dengan apa yang kita inginkan. Dan bicara sendiri memiliki perkembangan di dalam diri manusia. Kecerdasan interpersonal humanistik meliputi bicara yang baik terhadap orang lain.

Secara tersirat pada Surat 'Abasa menerangkan bagaimana kecerdasan interpesonal humanstik diterapkan oleh Nabi Muhammad Shollallahu alaih Wassalam. Musa kepada Fir'aun dengan perkataan lembut. ${ }^{6}$ Diharapkan dengan prilaku lembut tersebut dapat mengubah Fir'aun menjadi baik. Saat ini dibutuhkan seseorang yang mampu memahami orang lain. Agar kita tidak salah dalam memahami seseorang. Maka dibutuhkan suatu kecerdasan interpersonal humanistik dalam diri seseorang.

Dalam hadis Nabi Muhammad Saw memohon tiga permohonan hadis ini pun populer salah satunya agar umat Islam disatu padukan. Pertama, umatnya jangan kelaparan. Kedua ditenggelamkan. Ketiga terpecah belah atau pertikaian. Yang ketiga inilah tidak ada jawaban dari Allah swt. Jika kita melihat sejarah umat Islam masa lalu setelah kholifah empat umat Islam terbuai dengan berbagai macammacam kemewahan dan Nabi Muhammad Saw pun sudah memprediksi hal tersebut bahwa cinta dan dunia dan takut yang membuat kita tidak maju. ${ }^{7}$ Tetapi permintaan itu tidak dikabulkan.

Walaupun dalam arti Allah Swt tidak mengabulkan permintaan tersebut. Bagi orang yang beriman lebih baik kita mengantisipasi hal-hal tersebut. Jika tidak diantisipasi akan terjadi perang saudara. Karena menjelekkan Muslim satu dengan yang lain. Yang akhirnya membuat perpecahan diantara sesama Muslim. Contoh unik diterapkan Umar bin Abdul Aziz walaupun ia memiliki pasukan perang yang kuat dan hebat. Tapi ia lebih suka melakukan pendekatan kemanusiaan, dari pada megirimkan pasukan besar untuk menyerang orang yang tidak taat kepadanya. Bahkan pendekatan humanistik yang dilakukan Umar terhadap kaum Barbar yang berada di Afrika utara berhasil. Yang pada saat itu mereka terkenal dengan sebagai kelompok radikal. ${ }^{8}$ Oleh sebab itu, penulis kira penting melakukan penelitian ini.

\section{B. METODE}

Beberapa kajian telah meninyingung tentang kecerdasan Interpersonl yang bersifat umum. Di dalam buku tujuh kecerdasan yang ditulis Daniel Goleman

${ }^{5}$ M. Darwis Hude, Tentang Emosi Manusia di dalam Al-Qur'an (Jakarta: Penerbit Erlangga, 2006), 10.

${ }^{6}$ Hampir disetiap surat dalam Al-Qur'an mengisahkan Nabi Musa as.

${ }^{7}$ Ibnu Kastir, Tafsiru'l Qur'ani'l 'Azimi, jilid 4, 2000, 46-248.

${ }^{8}$ Majalah Bimas Islam, edisi no: 6/ III/2017, 74-75. 
menjelaskan secara umum tentang kecerdasan interpersonal dalam menghadapi seseorang yang bersifat sementara. Belum pada memanusiakan manusi itu sendiri. Begitu juga dengan teori kecerdasan majemuk (Multiple Intelligences) milik Howard Gardner. Ia sempat menyingung kecerdasan interpersonal yang masih bersifat umum.

Pada buku yang ditulis Mark K. Smith, dkk, Teori Pembelajaran dan Pengajaran hanya menjelaskan secara sekilas tentang Humanisme Klasik sehingga membuat penulis bertanya sesimple itu penjelasan tentang teori humanisme padahal jika melihat literature maka kemunculan paham humanisme begitu banyak. Salah satu tokohnya Abraham Maslow. Penelitian dilakukan oleh Okky Diasmoro dalam artikel psikologi terapan Universitas Muhammadiyah Malang, yang berjudul Hubungan Komunikasi Interpersonal dengan Kepuasan Kerja Karyawan Dewasa Awal Bagian Produksi PT. Gangsar Tulungagung. bahwa ada hubungan positif yang signifikan antara komunikasi interpersonal dengan kepuasan kerja pada karyawan dewasa awal bagian produksi PT. Gangsar Tulungagung $(r=0,406 ; p=0,000<0,01)$. Hasil tersebut dapat diartikan bahwa semakin tinggi komunikasi interpersonal (baik kemampuan komunikasi interpersonal) maka akan semakin tinggi pula kepuasan kerja yang dialami oleh karyawan dewasa awal bagian produksi PT. Gangsar Tulungagung, begitu pula sebaliknya. ${ }^{9}$ Pada buku lain yang ditulis M. Darwis Hude tentang Emosi di dalam Al-Qur'an. Walaupun sempat menyingung tentang kecerdasan interpersonal tapi penjelasannya tidak komperhenship.

Tujuan dari penelitian ini dalam rangka Pertama, untuk mengetahui penjelasan Al-Qur'an yang terkait dengan kecerdasan interpersonal humanistik dalam persepektif Al-Qur'an; Kedua, untuk menjelaskan prilaku-prilaku kecerdasan interpersonal humanistik dalam persepektif Al-Qur'an. Metode yang penulis gunakan dalam penelitian ini adalah metode kualitatif atau yang biasa di sebut studi kepustakaan. Menurut Jasa Ungguh Muliawan metode kualitatif adalah metode yang mengandalkan kekuatan pikiran memakai hukum logika yang legal, seperti sebab-akibat, jika-maka, aksi-reaksi, syarat-persyaratan atau prakondiasi. Syarat utama penelitian ini menggunakan nalar dan imajinasi yang sistematis. ${ }^{10}$

Sumber data terdiri dari data primer sumber data primer ini berasal dari teks Al-Qur'an dan hadist yang menjadi acaun penulis menggali penelitian tersebut. Dan data sekunder sumber data sekunder berasal dari data yang memuat tentang penjelasan mengenai kecerdasan interpersonal humanistik dari pihak lain. Pendapat ahli psikologi atau tulisan langsung yang meneliti tentang tema tersebut. Tekhnik pengumpulan data yang penulis lakukan diperoleh melalui buku-buku psikologi dan teks Al-Quran dan hadist. Penulis juga mengambil data dari seperti koran,

${ }_{9}$ Okky Diasmoro, “Hubungan Komunikasi Interpersonal dengan Kepuasan Kerja Karyawan Dewasa Awal Bagian Produksi PT. Gangsar Tulungagung", Jurnal Ilmiah Psikologi Terapan Universitas Muhammadiyah Malang, ISSN: 2301-8267 Vol. 05, No.01, (2017): 122.

10 Jasa Ungguh Muliawan, Metode Penelitian Pendidikan dengan Studi Kasus (Jogjakarta: Penerbit Gava Media, 2014), 60. 
doi.org/10.36671/andragogi.v1i3.66

jurnal, diskusi dan sumber data lainya. Yang nantinya data-data tersebut akan dipilah-pilah untuk penelitian lebih dalam. Setelah penulis mengumpulkan semua data maka penulis akan kembali mengecek data-data tersebut untuk dipisahkan menjadi data primer dan sekunder.

\section{HASIL DAN PEMBAHASAN \\ Definisi Kecerdasan Interpersonal}

Pengertian kecerdasan interpersonal menurut ahli psikologi ${ }^{11}$ kecerdasan interpersonal adalah kecerdasan yang dimiliki seseorang untuk berhubungan yang efektif dengan orang lain. Dalam kamus besar Bahasa Indonesia kecerdasan memiliki arti perbuatan mencerdaskan; kesempurnaan perkembangan akal budi (seperti kepandaian, ketajaman pikiran): perpustakaan didirikan untuk meningkatkan kecerdasan masyarakat. ${ }^{12}$ Definisi kecerdasan menurut Edward Thorndike yang dikutip oleh Baharuddin, "intelligence is demonstrable in abilitiy of the individual to make good responses from the stand point of truth or falt" (intelgensi ialah kemampuan individu untuk memberikan respon yang tepat, terhadap stimulus yang diterima). ${ }^{13}$ Sedangkan interpersonal berhubungan dengan orang lain. Maka jika digabungkan akan memliki makna kecakapan atau kepintaran dalam menghadapi berbagai macam orang. Dengan menilai emosinya, raut wajahnya, (tatapan mata, muka merah), genstur tubuhnya bahkan nada suaranya.

Dalam buku psikologi konsepsi dan aplikasi Jeffrey S. Nevid mengatakan bahwa kecerdasan (intelligensi, ketajaman pikiran) adalah "kecakapan umum individu untuk bertindak secara bertujan untuk berpikir secara nalar, dan rasional untuk menghadapi lingkungan secara efektif."14 Ketajaman pikiran inilah membuat seseorang dapat membaca dan mengendalikan pembicaraannya, baik dalam keadaan emosi yang stabil atau tidak. Dan ia berusaha membangun hubungan yang positif. Maka jelaslah bahwa kecerdasan tersebut digunakan untuk berhubungan, berintraksi, atau bergaul aktif dengan individu lainnya. Agar proses intraksi berjalan efektif dan positif. Positif menghilangkan kecurigaan terhadap orang yang kita ajak berintraksi.

Kecerdasan interpersonal ini berhubungan dengan feeling seperti yang diungkap Goleman dari Gardner feeling ada perasaan. Perasaan-perasaan diri

${ }_{11}$ Ilmu Psikologis adalah dasar yang memberikan informasi tentang bakat, minat, watak, karakter, motivasi dan inovasi peserta didik, pendidik, tenaga administrasi, serta sumber daya manusia yang lain. Dasar ini berguna juga untuk mengetahui tingkat kepuasan dan kesejahteraan batiniah pelaku pendidikan, agar mereka mampu meningkatkan prestasi dan kompetisi secara baik dan sehat. A. Haris Hermawan, Filsafat Pendidikan Islam cet. 2 (Jakarta: Direktorat Jenderal Pendidikan Agama Islam Kementrian Agama, 2012), 105.

${ }_{12}$ https://kbbi.kata.web.id/kecerdasan/ diakses. Jumat siang tanggal 28, Desember 2018.

13 Baharuddin, Pendidikan \& Psikologi Perkembangan (Jogjakarta: Penerbit Ar-Ruzz Media, 2009), 47.

${ }^{14}$ Jefrrey N. Nevid, Psikologi Konsep dan Aplikasi, diterjemahkan oleh M., Chozim dari judul Psikologi Consept and Applications (Bandung: Nusamedia, 2007), 510. 
seseorang dan kemampuan untuk membedakan perasaan-perasaan tersebut serta memanfaatkannya untuk menuntun tingkah laku. ${ }^{15}$ Artinya ketika berhubungan dengan manusia yang lain ada perasaan positif yang harus ditransfer. Perasaan positif akan menimbulkan pemahaman yang positif pula pada objek yang dihadapi. Oleh sebab itu perasaan sulit dibohongi ia akan terpancar di dalam raut wajah dan mata. Maka senyum yang tulus dan melahirkan dampak positif bagi yang melihatnya.

Dampak positif tersebut akan membaur keorang tersebut hingga menularkan kepada orang lain yang dihadapinya ataupun yang ia temui. Tapi sebaliknya ada kekacauan prilaku apabila kecerdasan interpersonal tidak diterapkan. Orang yang cenderung cepat marah, cepat mengambil kesimpulan. Bahkan langsung menghakimi. Yang bahaya jika ini terjadi pada pemimpin ketika ia menyebut sebuah kelompok atau orang tertentu dengan sebutan anti negaranya/radikal/teroris, dll. Maka hal ini akan memicu kelompok tersebut melawan atau bahkan memberontak. Hal ini membuat hubungan tidak harmoni. Antara masyarakat dan pemimpinan. Jika terjadi di perusahaan atasan dan bawahan atau karyawan dan manajer. Akan sulit terciptanya kedamaian majemukan.

Jika terjadi pada dua orang mungkin masih bisa didamaikan tapi jika terjadi pada suatu kelompok yang besar mungkin agak sulit. Dan biasanya memakan waktu yang lama. Karena melibatkan banyak pihak. Seharusnya seorang personal individu atau pun seorang pemimpin mencari tahu apa penyebabnya. Langkah apa yang harus dilakukan untuk meredam gejolak tersebut. Jika belajar pada tokoh Islam Umar bin Abdul Aziz ia melakukan tindakan yang persuasip terhadap golongan radikal suku Babar yang berada di Afrika Utara. Walaupun pada saat itu pasukan Umar bin Abdul Aziz sangat kuat. Bisa saja ia menyerang suku tersebut. Tapi ia lebih mengedepankan kecerdasan interpersonal humanistiknya dengan melakukan pendekatan manusiawi. Hingga gejolak dapat diredam. Oleh sebab itu bahwa kecerdasan interpsonal humanistik ini selain melihat sudut manusia maka sudut perilakunya layak untuk perhatikan. Karena mereka tidak hanya ingin dipenuhui kebutuhan hidupnya tapi juga dihargai jiwanya. Inilah yang disebutkan oleh Abraham Maslow dalam teori need herarki dengan menempatakan beberapa kebutuhan manusia.

Sebenarnya kebutuhan tertinggi manusia adalah keutuhan spiritual artinya apa ia bebas beribadah untuk menuju Tuhannya. Tidak dihalangi atau dilarang oleh aturan apa-pun. Dalam kehidupan kita saat ini sangat diperlukan bahkan menjadi sebuah kebutuhan bahwa berintraksi yang baik akan menimbulkan berbagai hal positif dalam kehidupan kita. Keakraban yang mudah terjalin, kebahagian karena memiliki teman.

${ }^{15}$ Daniel Goleman, Kecerdasan Emosi, diterjemahkan oleh T. Hermaya dari judul Emotion Intelligence (Jakarta: Penerbit Gramedia Pustaka Utama, 1999), 53. 
doi.org/10.36671/andragogi.v1i3.66

\section{Definisi Humanistik}

Pengertian Humanistik adalah paham yang memfokuskan pada individu seseorang baik dalam diri manusia maupun luarnya. Seperti yang terungkap dalam kamus ilmiah popular Arti Humanistik rasa kemanusian, berhubungan dengan manusia. ${ }^{16}$ Dalam ensiklopedi umum terbitan Kanisus. Humanisme muncul pada zaman renaissance yang awalnya memfokuskan kepada kesusastraan romawi dan yunani kuno dan prikemunisian. Istilah humanis adalah sebutan bagi paham humanisme seperti yang dianut tokoh-tokoh. ${ }^{17}$ Secara umum paham tersebut untuk menegaskan pada nilai-nilai dan Bahasa-bahasa yunani dan romawi dengan kesustraannya. ${ }^{18}$

Jauh sebelum Abraham Maslow terdapat tokok terkenal bernama Cicero (106$43 \mathrm{M})$, yang memebentuk pemahaman humanisme. Kata tersebut terpisah "humnisme" sebuah pemahaman hidup yang meletakan manusia pada posisi utama. Bebarapa tahun kemudian tokoh stonik ${ }^{19}$ Seneca (4SM-65M) mengatakan bahwa bagi umat manusia, manusia itu suci. Pendapat ini menjadi slogan humanis hingga sekarang. ${ }^{20}$ Menurut Abraham Maslow dianggap sebagai bapak psikologi humanistik yang menghadirkan teori yang komprehensif atau menyeluruh dan sangat jelas menunjukkan bahwa orientasi humanistik memiliki pengaruh yang besar terhadap pemikiran modern mengenai perilaku manusia.

Teori Maslow berdasarkan pada anggapan bahwa setiap individu memiliki dua hal di dalam dirinya: 1. Adanya usaha yang positif untuk berkembang. 2. Adanya kekuatan untuk melawan atau memberi penolakan terhadap perkembangan itu. Dan menurut Yusuf Syamsu teori humanistik dapat diartikan sebagai orientasi bersifat teoritis yang menekankan kepada keunikan kualitas manusia khususnya berhubungan dengan free will atau kehendak bebas dan potensi untuk mengembangkan diri. ${ }^{21}$ Otong Surasman, sempat menyingung psikologi humanistik dalam bukunya Bercermin pada Nabi Ibrahim as. Bahwa psikologi humanistic berada pada aspek nafsiah, tepatnya pada dimensi an-nafs, al-'aql, dan al-qalb.

${ }_{16}$ Burhani MS dan Hasbi Lawrens, Kamus Ilmiah Populer (Jombang: Penerbit Lintas Media, t.th), 159 .

17 Diantaranya Boccaccio, Petrarchus, Lorenzo Valla, Lorenzo de Medeci, Erasmus dan Thomas More. Lihat Ensiklopedi Umum, 434.

${ }_{18}$ Abd Aziz, Saihu, "Interpretasi Humanistik Kebahasaan: Upaya Kontekstualisasi Kaidah Bahasa Arab" Arabiyatuna, Vol. 03, No. 2 (2019): 299-314.

19 Stonik berasal dari kata Yunani yang bearti "serambi" paham ini ikut memperngaruhi kebudayaan Romawi. Kaum Stonik percaya bahwa orang adalah bagian dari akal atau logos yang sama. Mereka menganggap bahwa setiap ornag adalah seperti dunia miniature atau mikroksmos, yang merupakan cerminan makrokosmos. Hal ini mendorong pada pemikiran bahwa ada suatu kebenaran universal yang dinamakan hokum alam. Dan karena itu hukum alam itu berdasarkan akal manusia yang abadi dan universal. Mirip pemahaman Soctrates.

${ }^{20}$ Jostein Gaarder, Dunia Spohie (Bandung: Penerbit Mizan, 2018), 215.

${ }^{21} \mathrm{https}: / /$ dosenpsikologi.com/teori-psikologi-humanistik, diakses tanggal 25-4-2019 
Psikologi ini memusatkan pada perhatian pada sisi kualitas kemanusian, berupa pikiran, perasaan, dan kemampuan. ${ }^{22}$

Jeffrey S. Nevid mengatakan Maslow mendorong manusia untuk mencapai aktulisasi-diri. Hal tersebut merupakan motivasi untuk mengembangakn pontensi yang ada dalam diri kita. Maslow berkeyanina jika seseornag di beri kesempatan ia akan berusaha menuju aktulisasi diri. Dalam pandangan humanistik kperibadian dipadangn paling baik jika ada proses kelanjutan pertumbuhan dan realisasi personal. ${ }^{23}$ Humanisme dimaknai sebagai potensi (kekuatan) individu untuk mengukur dan mencapai ranah Ketuhanan (transendensi) serta mampu menyelesaikan persoalan-persoalan sosial. Humanisme dalam pendidikan Islam adalah proses pendidikan yang lebih memperhatikan aspek potensi manusia sebagai makhluk berketuhanan dan makhluk berkemanusiaan serta individu yang diberi kesempatan oleh Allah untuk mengembangkan potensi-potensinya. Di sinilah urgensi pendidikan Islam sebagai proyeksi kemanusiaan (humanisasi). ${ }^{24}$

Tokoh lain yang menyingung Teori humanistik Rogers lebih penuh harapan dan optimis tentang manusia karena manusia mempunyai potensi-potensi yang sehat untuk maju. Dasar teori ini sesuai dengan pengertian humanisme pada umumnya, di mana humanisme adalah doktrin, sikap, dan cara hidup yang menempatkan nilai-nilai manusia sebagai pusat dan menekankan pada kehormatan, harga diri, dan kapasitas untuk merealisasikan diri untuk maksud tertentu, yang nantinya akan dihubungkan dengan pembelajaran atau pendidikan yang manusiawi.

Rogers dalam bukunya Freedom to Learn, yang dikutip oleh Khusnul Mualim, prinsip-prinsip dasar humanistik yang penting diantaranya ialah: 1) Manusia itu mempunyai kemampuan belajar secara alami; 2) Belajar yang signifikan terjadi apabila materi pelajaran dirasakan murid mempunyai relevansi dengan maksudmaksud sendiri; 3) Belajar yang menyangkut perubahan di dalam persepsi mengenai dirinya sendiri diangap mengancam dan cenderung untuk ditolaknya; 4) Tugastugas belajar yang mengancam diri ialah lebih mudah dirasakan dan diasimilasikan apabila ancaman- ancaman dari luar itu semakin kecil; 5) Apabila ancaman terhadap diri siswa rendah, pengalaman dapat diperoleh dengan berbagai cara yang berbedabeda dan terjadilah proses belajar; 6) Belajar yang bermakna diperoleh siswa dengan melakukannya; 7) Belajar diperlancar bilamana siswa dilibatkan dalam proses belajar dan ikut bertanggungjawab terhadap proses belajar itu; 8) Belajar inisiatifsendiri yang melibatkan pribadi siswa seutuhnya, baik perasaan maupun intelek, merupakan cara yang dapat memberikan hasil yang mendalam dan lestari; 9) Kepercayaan terhadap diri sendiri, kemerdekaan, kreativitas, lebih mudah dicapai

22 Otong Surasman, Bercermin pada Nabi Ibrahim (Jakarta: Penerbit Perspektif, 2016), 118.

${ }^{23}$ Jeffrey, S. Nevid, Psikologi Konsepsi dan Aplikasi, diterjemahkan oleh M. Chozim dari judul Psikologi Consept and Applications (Bandung: Nusamedia, 2007), 953-955.

24 Khusnul Mualim,"Gagasan Pemikiran Humanistik," Al-ASASIYYA: Journal Of Basic Education, Vol. 01 No. 02 (2017): 999 
doi.org/10.36671/andragogi.v1i3.66

terutama jika siswa dibiasakan untuk mawas diri dan mengritik dirinya sendiri dan penilaian dari orang lain merupakan cara kedua yang penting; 10) Belajar yang paling berguna secara sosial di dalam dunia modern ini adalah belajar mengenai proses belajar, suatu keterbukaan yang terus-menerus terhadap pengalaman dan penyatuannya ke dalam diri sendiri mengenai proses perubahan itu. ${ }^{25}$

Kalau menurut peneliti sendiri humanistik adalah suatu sikap yang adil terhadap manusia. Manusia miliki hak dalam dirinya. Hak untuk berkembang lebih baik, hak itu menyakini agama tertentu. Dan hak untuk memperoleh kehidupan yang utuh secara individu dan social. Karena dari kedua itulah muncul sebuah pemahaman dalam diri munusia. Yang membuahkan pengalaman dan ilmu.

Hal tersebut menjadi landasan manusia untuk berpikir. Jika saya berbuat baik dengan tersenyum saja kepada orang yang tidak dikenal. Maka saya membuat pengalaman baru. Apalagi ketika orang merespon senyuman tersebut dengan hal yang positif. Maka muncullah sikap berlaku sebaliknya kepada yaitu adil menempatkan seseorang sesuai tempatnya. Dan jika perbuatan tersenyum dianggap aneh atau bahkan dicemooh. Mungkin orang tersebut belum belajar tersenyum dengan lebih baik.

\section{Implementasi Kecerdasan Interpersonal Humanistik}

Pada pembahasan ini akan dijelaskan bagaimana implementasi kecerdasan interpersonal humansitik dalam perspektif Al-Qur'an. Hal ini dibagi dua bagian yang kecerdasan interpersonal humanistik dalam Al-Qur'an pertama prilaku positif dan prilaku negatif (artinya yang harus dihindari untuk mempertajam prilaku kecerdasan interpersonal humanistik). Tetapi sebelum itu kita tinjuan dahulu arti kata implementasi. Implementasi dalam kamus besar bahasa Indonesia memiliki arti-im.ple.men'ta.si atau impleméntasi, pelaksanaan, penerapan. ${ }^{26}$ Dalam kamus ilmiah populer Implementasi memiliki arti sebuah pelaksanaan, penerapan atau kerlibatan. ${ }^{27}$ Dalam hal ini kecerdasan interpersonal humanistik dalam perspektif Al-Qur'an dapat dilaksanakan atau diterapkan dalam kehidupan yang nyata melibatkan pelaku kecerdasan interpersonal humanistik. Yaitu manusia, dan kelompok manusia yang lain. Al-Qur'an selalu menanamkan jiwa-jiwa positif pada pembacanya. Agar manusia tersebut berprilaku positif. Terkadang seorang muslim yang serius membaca Al-Qur'an akan terhayut dalam pernyataan-pernyataan AlQur'an.

Ketika Al-Qur'an dibaca bukan hanya keluar suara yang indah seperti berpuisi atau bersyair. Tapi ia mengajak akal manusia untuk berpikir positif dan bertindak positif pula. Dalam keadaaan apa-pun. Hal inilah yang nantinya membuat

25 Khusnul Mualim, "Gagasan Pemikiran Humanistik" Al-ASASIYYA: Journal Of Basic Education, Vol. 01 No. 02 (2017): 8.

${ }^{26}$ https://www.kbbi.web.id/implementasi, diakses jumat siang tanggal 28, Desember 2018.

${ }^{27}$ Burhani MS dan Hasbi Lawrens, Kamus Ilmiah Populer, (Jombang: Penerbit Lintas Media), 207. t.th. 
kecerdasan interpersonal humanistic dapat diterapkan sebagai landasan terpadu dalam kehidupan manusia. Yang menjadikan kecerdasan interpersonal humanistic dibangun baik dari dalam dan luar. Dari dalam apa yang dapat menjadikan kecerdasan interpersonal humanistik menjadi sebuah kompenen yang kuat sedangkan eksternal adalah sebagai penguatnya. Maka penelitian ini dibagi menjadi dua faktor. Pertama Internal dan eksternal, apa yang dibangun dan diimplementasikan dalam diri seorang kecerdasan interpersonal humanistik yaitu berupa Prilaku positif seperti yang diungkapkan pada Surat 'Abasa/80: 1-13.

\section{Berbagi/sharing Nasehat dengan sabar dan berbagi kebenaran dalam Surat Al- ‘Ashar}

Kecerdasan interpersonal humanistik tidak hanya sebatas pada anggota tubuh yang berfungsi dengan positif tapi termasuk dari kecerdasan interpersonal humanistic. Mereka yang dalam intraksi sosialnya memberikan hal yang bermanfaat baik berbagi secara materi ataupun immateri. Terutama untuk saling menasehati dalam kebaikan. Maka hal ini termaktub pada Surat Al-'Ashar/103: 1-3 sebagai berikut,

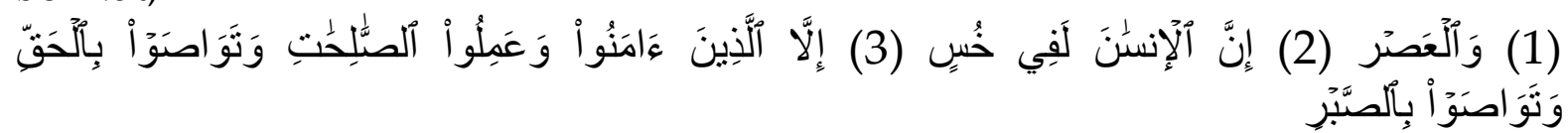

1. Demi masa.

2. Sesungguhnya manusia itu benar-benar dalam kerugian,

3. Kecuali orang-orang yang beriman dan mengerjakan amal saleh dan nasehat menasehati supaya mentaati kebenaran dan nasehat menasehati supaya menetapi kesabaran.

Terlihat pendek Surat tersebut tapi apabila dicermati lebih dalam menurut Imam Syafei yang dikutip oleh Wahbah Az-Zuhailii dalam Tafsir Al-Muniir bahwa Surat Al-'Ashar seandainya manusia serius memikirkannya dengan mendalam pastilah Surat ini cukup menjadi pelajaran bagi mereka. ${ }^{28}$ Pada Surat Al-'Ashr/103:1. Menjelaskan tentang waktu. Waktu tidak memiliki ruang dan batas. Waktu bergerak sepanjang detik dan bersifat dinamis. Allah sudah menetapkan waktu dengan hokum sunnatullah-Nya. Waktu akan terasa sangat lambat jika tidak ada aktifitas. Tapi sebaliknya waktu terasa cepat jika ada aktifitas di dalamnya. Waktu sangat penting dalam kehidupan manusia. Waktu dapat menentukan orang tersebut gagal atau tidak. Oleh sebab itu Allah memberi peringatan tentang waktu. ${ }^{29}$

Selain, bersabar kecerdasan Interpersonal Humanistik harus dibangun dengan kepekaan Intelektualitas yang tinggi. Kepekaan dalam Kamus Besar Bahasa Indonesia berarti perihal mudah bergerak atau kesanggupan bereaksi terhadap

${ }^{28}$ Wahbah Az-Zuhailii, Tafsir al-Munir, jilid 15, Terj. oleh Abdul Hayyie, dkk, judul asli atTafsiirul -Muniir: Fiil 'Aqidah wasy-Syarii'ah wal Manhaj (Jakarta: Penerbit Gema Insani Press, 2017), 661.

${ }^{29}$ T. H. Thalhas, et.al., Tafsir Pase Kajian Surah Al-Fatihah dan Surah-surah dalam Juz'amma, Cet. 1 (Jakarta: Penerbit Bale Kajian Tafsir Al-Qur'an Pase, 2001), 173-174. 
doi.org/10.36671/andragogi.v1i3.66

suatu keadaan. ${ }^{30}$ Intelektualitas memiliki arti tingkat kecerdasan yang tinggi. ${ }^{31}$ Artinya ia gemar menuntut ilmu. Sehingga kemampuan dalam dirinya dapat meningkat. Bukan hanya senang menuntut ilmu ia juga berusaha mengamalkan ilmu tersebut. Karena hal tersebut menjadi basik dasar otak dan hatinya dalam rangka memperluas cakrawala sudutnya pandangnya sebagai manusia di muka ini. Seperti yang diterangkan Surat Al-'Alaq/96:1-7 dibawah ini,

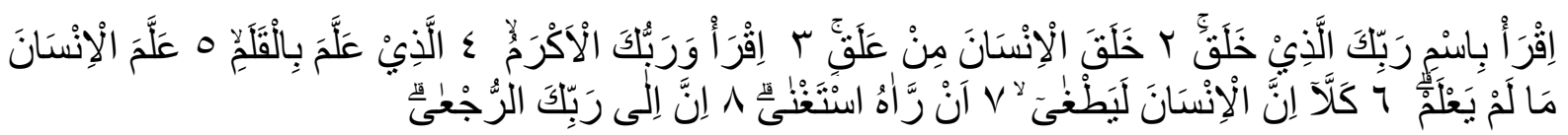

1. Bacalah dengan menyebut Asma Allah Tuhanmu yang telah menciptakan.

2. Allah telah menciptakan manusia dari segumpal darah.

3. Bacalah dan Tuhanmulah yang maha mulia

4. Yang mengajarkan manusia dengan perantara pena

5. Yang telah mengajarkan kepada manusia yang tidak diketahuinya.

6. Sekali-sekali tidak!sungguh, manusia itu benar-benar melampaui batas

7. Apabila melihat dirinya serba cukup

8. Sesungguhnya hanya kepada Tuhanmulah tempat kembali.

Ayat pertama ini, menjelaskan permulaan pertama, rahmat Allah memerintahkan manusia membaca (mempelajari, meneliti, dan sebagainya.) apa saja yang telah Ia ciptakan, baik ayat-ayat-Nya yang tersurat (qauliyah), yaitu Al-Qur'an, dan ayat-ayat-Nya yang tersirat, maksudnya alam semesta (kauniyah. Membaca itu harus dengan nama-Nya, artinya karena Dia dan mengharapkan pertolongan-Nya. Dengan demikian, tujuan membaca dan mendalami ayat-ayat Allah itu adalah diperolehnya hasil yang diridai-Nya, yaitu ilmu atau sesuatu yang bermanfaat bagi manusia. Kedua, tentang ilmu pengetahuan yang berada dalam otak manusia, terkadang pada lidah manusia, atau pun pada jari-jari manusia untuk mengungkapkan apa yang ada dalam otaknya. ${ }^{32}$

Ayat kedua ini. Allah menyebutkan bahwa di antara yang telah Ia ciptakan adalah manusia, yang menunjukkan mulianya manusia itu dalam pandangan-Nya. Allah menciptakan manusia itu dari 'alaqah segumpal darah, yakni telur yang sudah terbuahi sperma, yang sudah menempel di rahim ibu. Kemudian Segumpal darah berkembang menjadi manusia dan dilahirkan ke dunia ini. Lengkap dengan akal pikiran, ilmu pengetahuan dan kekuasaan untuk menundukkan makhluk lain di muka bumi ini. ${ }^{33}$ Wahbah Az-Zuhaili mengatakan kata عَلَق merupakan jamak dari

30 https://kbbi.kemdikbud.go.id, Diakses tanggal 1 September 2019.

${ }^{31}$ Burhani MS dan Hasbi Lawrens, Kamus Ilmiah Populer (Jombang: Penerbit Lintas Media, t.th.), 221.

32 Ibnu Katsir, Tafsir Ibnu Katsir Juz 'Amma, diterjemahkan oleh Farizal Tirmizi dari judul Tafsir Juz 'Amma Tafsir Al-Qur'an Al-'Azhim, (Jakarta: Penerbit Pustaka Azzam), cet. 15, Nopember 2013, 265.

33 T.H. Thalhas, et.al., Tafsir Pase Kajian Surah Al-Fatihah dan Surah-Surah dalam Juz'Amma, (Jakarta: Penerbit Bale Kajian Tafsir Al-Qur'an Pase), 2001, 248. 
'alaqah yang berarti gumpalan darah yang beku pada seluruh penciptaan manusia. Jadi seluruh manusia penciptaannya melalui pase ini. Maka kata ini menjadi penguat kata sebelumnya bahwa Allah adalah Tuhan yang maha mulia dengan segala kekuasaan-Nya. ${ }^{34}$

\section{Tidak Over konfident (Merasa paling benar dalam Surat Al-Hujarat/Kamar- kamar)}

Over konfident dapat diartikan berlebihan atau kelebihan dalam perbuatan. ${ }^{35}$ Sedangkan konfident berarti percaya diri menjadi kata sifat. ${ }^{36}$ Dalam Pelaku kecerdasan Interpersonal Humanistik harus memperhatikan hal ini dalam dirinya. Karena dirinya akan berinteraksi dengan orang lain. Terutama tidak berlebihan dalam bersikap. Baik menganggap dirinya paling benar ataupun berprasangka buruk terhadap lawan bicaranya atau saudaranya yang sudah ia kenal. Jika kita memaknai secara filosofis tentang arti Surat ini yang berarti kamar-kamar. Kita diperintahkan untuk tidak banyak mengumbar sesuatu hal yang bersifat pribadi secara berlebihan yang membuat kita lupa bahwa kita memiliki aib yang harus kita tutup seperti pintu kamar pribadi kita. Tak boleh ada yang tahu kecuali diri kita dan Allah swt.

Hamka dalam Tafsir Al-Azhar mengatakan di samping sikap hormat terhadap Rasol Surat Al-Hujarat mengajarkan sopan-santun dalam kehidupan antara Muslim yang satu dengan yang lainnya. Bersikap lemah-lembut, berlaku hormat, jangan mencela dan jangan memburukkan orang lain. Bahwasanya antara iman dan peergaulan sopan dan santun tidak bisa dipisahkan. ${ }^{37}$ Pada ayat 10 surat Al-Hujarat terang benderang Allah swt memberikan panduan kepada orang beriman dalam menghadapi sebuah persilihan. Artinya apabila ada seorang muslim yang berselisih harus mampu menjadi penerang bagi suadara Muslim lain yang sedang bersengketa. Hal tersebut dibutuhkan dalam pembentukan kecerdasan interpersonal humanistik. Bahwa kita harus memutuskan dengan adil. Baik dari perkataan dan perbuatan.

\section{Pendidikan Interaksi Efektif}

Pendidikan Dialog yang efektif diimplemnetasikan oleh Lukman Al-Hakim terhadap anaknya. Sebuah interaksi penuh makna antara seorang ayah dan anak.

${ }^{34}$ Wahbah Az-Zuhailii, Tafsir al-Munir, jilid 15, diterjemahkan oleh Abdul Hayyie, dkk, judul asli at-Tafsiirul-Muniir: Fiil 'Aqidah wasy-Syarii'ah wal Manhaj, (Jakarta: Penerbit Gema Insani Press), cet.2, Juni 2017, 596.

${ }^{35}$ Burhani MS dan Hasbi Lawrens, Kamus Ilmiah Populer (Jombang: Penerbit Lintas Media, t.th), 482 .

${ }^{36}$ Burhani MS dan Hasbi Lawrens, Kamus Ilmiah Populer, 306.

${ }^{37}$ Hamka, Tafsir Al-Azhar, jilid 9 (Singapura: Penerbit Pustaka Nasional PTE LTD, 2003), 6807. 
doi.org/10.36671/andragogi.v1i3.66

Interaksi dapat diartikan keadaan saling berhubungan untuk mempengaruhui. ${ }^{38}$ Pada hal ini, bagaimana Lukman Al-Hakim memberi nasehat kepada anaknya dengan lemah lembut. Hal ini harus dimiliki oleh seorang Muslim saat mereka sedang berintraksi dengan audies entah, orang tua. Terlebih lagi anak-anak. Baik anak kita sendiri atau pun anak orang lain dalam rangka sebuah pendidikan karakter. Menjelaskan sebuah peraturan dari Allah swt berat tapi ia dapat menerima. Seperti yang tercantum pada Surat Lukman/31:12-19.

\section{Pendidikan Dialog Ketegasan antara Nabi Ibrahim dan Ayahnya}

Kecerdasan Interpersonal harus memiliki prinsip tegas dalam berdialog. Dialog dapat diartikan sebuah percakapan. ${ }^{39}$ Terutama mengenai masalah aqidah. Seperti yang tertera pada Surat Maryam/19:41-46. Maka diperlukan dialog-dialog yang hangat terhadap orang tua dan anak. Jika di rumah sudah merasa dihargai dengan kasih sayang. Maka implentasi kepada sekitarnya pun sama. Seorang anak akan menyayangi pada lingkungan sekitarnya. Baik teman, guru, atau orang lain. Pada orang akan dibahas pada dialog Nabi Musa dan Fir'aun.

\section{Percaya Tuhan/Beliveng God}

Pada Surat Al-Ikhlas. Quraisy Shihab mengatakan bahwa tujuan dari Surat Al-Ikhlas adalah dalam rangka mengenalkan Allah swt yang berhak disembah oleh Nabi Muhammad saw. Dan kaum Muslim memantapkan keyakinannya tentang keesaan Allah swt dalam Zat, sifat dan Perbuatan-Nya. ${ }^{40}$ Percaya Tuhan beliveng good pada Surat tersebut membuat Kecerdasan Interpersonal Humanistik untuk berbuat baik. Percaya Tuhan. Ia pecaya dengan keesaan Allah swt. Yang maha tunggal dapat berdiri sendiri. Seperti yang disingung Surat Al-Ikhlas/112:1-3 di bawah ini,

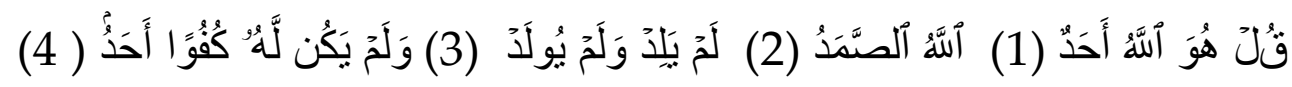

1. Katakanlah: "Dialah Allah, Yang Maha Esa.

2. Allah adalah Tuhan yang bergantung kepada-Nya segala sesuatu.

3. Dia tiada beranak dan tidak pula diperanakkan, dan tidak ada seorangpun yang setara dengan Dia

Kecerdasan interpersonal tidak hanya sebatas pada prilaku individu bertautan dengan individu lainya. Ia juga harus memiliki tautan dengan Tuhan. Begitulah ajaran Islam. Bahwa orang-orang yang beriman diciptakan dalam rangka beribadah kepada Allah swt. Bahkan pesan Nabi-nabi di dalam Al-Quran yang pertama tentang teologi keesaan Tuhan. Muslim hanif. Keyakinan inilah yang

38 https://kbbi.kemdikbud.go.id, Diakses tanggal 30 September 2019.

39 Burhani MS dan Hasbi Lawrens, Kamus Ilmiah Populer (Jombang: Penerbit Lintas Media, t.th, 91 .

${ }^{40}$ M. Quraisy Shihab, Al-Lubaab (Makna, Tujuan dan Pelajaran dari Al-Fatihah dan Juz 'Amma) (Tangerang: Penerbit Lentera Hati, 2008), 336. 
mengarahkan orang beriman untuk mencintai saudara-saudara seimannya. Bagaimana bersikap yang baik orang lain.

\section{KESIMPULAN}

Dari penjelasan, pengolahan data yang bersifat analisis yang peneliti lakukan tentang kecerdasan interpersonal humanistik dalam perspektif Al-Qur'an dengan pemaparan dari bab-bab maka dapat memberikan kesimpulan sebagai berikut: Pertama, kecerdasan interpersonal terkait dengan manusia yang menginginkan hubungan baik antara yang satu dengan yang lain. Agarnya terciptanya hubungan yang hamoni dalam kehidupan. Tentunya, hal inilah yang kita butuhkan karena pada dasarnya manusia mahluk yang terhubung dengan mahkluk lainya. Baik manusia atau pun non-manusia. Kedua, menempatkan posisi manusia dengan penuh harapan dan optimis pada nilai-nilai manusia sebagai pusat dan menekankan pada kehormatan, harga diri, dan kapasitas untuk merealisasikan diri untuk hal tertentu.

Kecerdasan interpersonal humanistik dalam perspektif Al-Qur'an terbagi menjadi dua. Pertama Internal. Kedua eskternal. Hal dilakukan untuk mengantisipasi sikap atau prilaku yang bertentangan dengan kecerdasan interpersonal humanistik. 1. Internal berisi: a. Repleks Positif terhadap orang yang berkebutuhan khusus, yang diterangkan dalam Surat 'Abasa/80: 1-4, b. Tidak Menyakiti dengan Tangan, yang termaktub dalam Surat Al-Lahab/111:1-5 dan Surat Al-Humazah/104:1-2, c. Berbagi /Share Nasehat, yang dijelaskan pada Surat Al-'Ashar/103: 1-3, d. Kepekaan Intelektualitas, yang terdapat Surat Al-'Alaq/96:1-7, e. Tidak Over Konfident, yang tertulis pada Surat al-Hujarat/49:10-13, f. Pendidikan Dialog Efektif, yang tersurat pada Surat Lukman/31:12-19, g. Pendidikan Dialog Ketegasan, pada Surat Maryam/19:41-46, h. percaya Tuhan/ Beliveng good, yang tercantum Surat AlIkhlas/112:1-3. 2. Eksternal berisi: a. Menjaga Toleransi, yang dijelaskan Surat AlKafirun/109:1-6, b. Tidak berlebihan. Lebih baik minimalis, yang diterangkan dalam Surat At-Takastur/ 102:1-2, c. Menjaga Iman dan Keamanan, yang dijelaskan Surat Quraisy/106:1-4, d. Menjaga Dialog yang sehat terdapat dalam Surat Thaha/20:41-44.

Berdasarkan penjelasan diatas dan hasil temuan yang dilakukan peneliti ingin berikan beberapa saran sebagai berikut: Pertama, Lembaga pendidikan diharapkan untuk menerapkan kecerdasan interpersonal humanistik pada setiap kegiatan pembelajaran sekolah. Hal tersebut dalam rangka pembentukan sejak dini agar mereka dapat menghargai saudara mereka dan orang lain; Kedua, Perlu ada upaya pencerahan yang dipelopori oleh para peneliti lain untuk memadukan keilmuan Islam dan modern agar Islam dapat memberikan pencerahan kepada Muslim pribadi dan umumnya umat lain. 
doi.org/10.36671/andragogi.v1i3.66

Aziz, Abd, Saihu, "Interpretasi Humanistik Kebahasaan: Upaya Kontekstualisasi Kaidah Bahasa Arab" Arabiyatuna, Vol. 03, No. 2 (2019): 299-314.

Az-Zuhailii, Wahbah. Tafsir al-Munir, jilid 15, diterjemahkan oleh Abdul Hayyie, et,al., judul asli at-Tafsiirul -Muniir: Fiil 'Aqidah wasy-Syarii'ah wal Manhaj, Jakarta: Penerbit Gema Insani Press, cet.2, Juni 2017.

Alqasimi, Muhammad Jamaluddin. Bimbingan untuk mencapai tingkat Mu'min, diterjemahkan oleh Moh. Abdai Rathomy dari judul Ihya 'Ulumuddin, Bandung: Penerbit Diponegoro, 1975.

Baidan, Nasruddin. Metode Penafsiran Al-Qur'an Kajian terhadap Ayat-ayat yang Beredaksi Mirip, Jogjakarta: Pustaka Pelajar, 2002.

Basyir, Hikmat. et.al., Tafsir Muyassar, jilid 2 diterjemahkan oleh Muhammad Ashim dan Izzudin Karim dari judul At-Tafsir al-Muyassar, Jakarta: Darul Haq, cet. 1, 2018.

Burhani MS dan Hasbi Lawrens, Kamus Ilmiah Populer, Jombang: Penerbit Lintas Media, t.th.

Diasmoro, Okky. "Hubungan Komunikasi Interpersonal dengan Kepuasan Kerja Karyawan Dewasa Awal Bagian Produksi PT. Gangsar Tulungagung", Jurnal Ilmiah Psikologi Terapan Universitas Muhammadiyah Malang, Vol. 05, No. 01 (2017): 122.

Goleman, Daniel. Kecerdasan Emosi, diterjemahkan oleh T. Hermaya dari judul Emotion Intelligence, Jakarta: Penerbit Gramedia Pustaka Utama, cet. 8 April 1999.

Hude, M. Darwis. Tentang Emosi Manusia di dalam Al-Qur'an, Jakarta: Penerbit Erlangga, 2006

Muliawan, Jasa Ungguh. Metode Penelitian Pendidikan dengan Studi Kasus, Jogjakarta: Penerbit Gava Media, cet. 1, 2014.

Nevid, Jeffrey, S. Psikologi Konsepsi dan Aplikasi, diterjemahkan oleh M. Chozim dari judul Psikologi Consept and Applications. Bandung: Nusamedia, 2007.

Surasman, Otong. Bercermin pada Nabi Ibrahim, Jakarta: Penerbit Perspektif, 2016.

Tafsir 'Ilmi, Science Dalam Perspektif Al-Qur'an dan Sains, disusun atas kerjasama Lajnah Pentahsih Mushaf Al-Qur'an Badan Litbang \& Diklat Kementerian Agama RI dengan LIPI, Jakarta: Penerbit Legalitas, 2013, Edisi 1, hal. 797.

Mualim, Khusnul. "Gagasan Pemikiran Humanistik," Al-ASASIYYA: Journal Of Basic Education, Vol. 01 No. 02 (2017): 3.

Hamka,. Tafsir Al-Azhar, jilid 9, Singapura: Penerbit Pustaka Nasional PTE LTD, Cet. 2003

Thalhas, T. H. et.al. Tafsir Pase Kajian Surah Al-Fatihah dan Surah-Surah dalam Juz'Amma, Jakarta: Penerbit Bale Kajian Tafsir Al-Qur'an Pase, 2001.

Shihab, M. Quraisy. Al-Lubaab (Makna, Tujuan dan Pelajaran dari Al-Fatihah dan Juz 'Amma), Tangerang: Penerbit Lentera Hati, cet. 1, Agustus 2008. 